\title{
Imitation and production of interval ratios
}

\author{
JEFFERY J. SUMMERS, SIMON R. HAWKINS, and HELEN MAYERS \\ University of Melbourne, Parkville, Victoria, Australia
}

\begin{abstract}
This study examined the imitation and production of interval ratios by musicians and nonmusicians. In particular, we compared the accuracy of reproduction or production of temporal patterns that theoretically evoke either a metrical or a nonmetrical interpretation (Essens \& Povel, 1985). For the imitation task (Experiment 1), metrically structured patterns were more accurately reproduced than nonmetrically structured patterns. Performance in the production task (Experiment 2), however, was similar for the two types of patterns. The results suggest that the internal representation of a pattern depends not only on the structural characteristics of the pattern, but also on the task a person is required to perform. An alternative hypothesis, that different strategies were employed by subjects in the performance of the two tasks, is also considered.
\end{abstract}

Recent psychological models of temporal pattern perception typically assume the existence of an internal structure on which subjects attempt to map presented temporal sequences. Accurate imitation of temporal patterns depends, therefore, on the degree to which the structure of the presented sequence fits the structure of the internal representation. Early behaviorist theories proposed that a sequence of events is represented as a series of durations in which adjacent intervals are chained by simple S-R bonds (Jones, 1978). The inability of a chain-like representation of durations to account for the organizational tendencies evident in the perception and production of temporal sequences (e.g., Fraisse, 1956), however, has led modern theorists to focus upon the time relations between intervals in a sequence.

Although a number of "relative timing" theories have been proposed, two general categories can be distinguished. The first suggests that the grouping characteristics evident in the perception of temporal patterns are governed by Gestalt-like principles. Fraisse $(1956,1978)$ has argued that subjects are able to distinguish between only two time categories: short times and long times. Within each category, assimilation occurs, that is, a tendency to equalize similar durations. Among durations of differing categories, there is a tendency to exaggerate the time differences (distinction) with a preference for a long/short ratio of 2:1. Furthermore, in sequences involving both short and long intervals between sounds, a series of short intervals will be perceived as a group (law of proximity).

The second class of theories proposes that temporal pat-

This research was supported by the Australian Research Grants Scheme, Project No. A28115899. Software development for controlling stimuli and acquiring data was carried out by Rod Dickinson. We are grateful to Susan Fealy, Joe Gazis, and Elizabeth Hinton for their help in analyzing the data. Requests for reprints should be sent to Jeffery Summers, Department of Psychology, University of Melbourne, Parkville, Victoria, Australia 3052. terns are encoded hierarchically (e.g., Martin, 1972; Povel, 1981; Vorberg \& Hambuch, 1978). A basic assumption of most hierarchical models is that subjects detect underlying "beats" that occur at equal time intervals throughout a sequence. The beat interval is then used to organize other shorter intervals in the pattern. Povel (1981) has further argued that only a limited number of within-beat structures are possible. Beat intervals may be empty, filled with equal intervals, or filled with unequal intervals that relate as 1:2 or 1:3 (Essens \& Povel, 1985).

Much attention has recently been given to the factors influencing the detection of beats in temporal sequences (Longuet-Higgins \& Lee, 1982; Povel, 1984; Povel \& Essens, 1985; Steedman, 1977). For example, Povel and Essens (1985) have proposed the existence of an internal clock that is used to specify the temporal structure of a presented pattern. Whether or not an internal clock is generated depends on the structural characteristics of the pattern. In particular, the divisibility of a sequence into equal time intervals and the distribution of perceived accents are important factors in clock induction. Temporal patterns that do not allow a metrical interpretation will be organized according to the Gestalt principles outlined previously.

Support for the distinction between metrical and nonmetrical coding has come from studies of the reproduction of simple temporal patterns with varying interval ratios. Povel (1981) and Essens and Povel (1985) have shown that patterns that allow a metrical interpretation are imitated more accurately than those that do not. Furthermore, similarities in the performance of musically trained and untrained subjects suggested that the cognitive structures involved in the perception of temporal patterns may be of universal origin (Povel, 1981). Smith (1983), however, has argued that skilled and unskilled subjects may have different psychological representations of rhythmic structures. She found that musically skilled subjects were able to make use of higher order properties in a sequence, using the beat as a temporal frame- 
work, whereas nonmusicians' responses reflected an organization based on temporal proximity.

The present study was designed to further examine the distinction between metrical and nonmetrical representations of temporal patterns. In particular, we compared the performance of musically trained and untrained subjects in tasks involving the imitation (Experiment 1) and production (Experiment 2) of simple temporal patterns that varied in the relative durations of their component intervals. $^{1}$

\section{EXPERIMENT 1}

In this experiment, a continuation procedure was used. This consisted of an induction phase in which subjects attempted to synchronize with a sequence of tones, followed by a continuation phase in which the subject tried to reproduce the pattern previously induced. Greeno and $\mathrm{Si}$ mon (1974) have suggested that such imitation tasks involve three distinct processes: (1) identification of the structural characteristics of the pattern; (2) coding and storage of the perceived pattern in memory; and (3) use of this stored representation to generate the required sequence of timed responses. In such tasks, therefore, accurate imitation of temporal patterns depends on the extent to which they are accurately perceived.

\section{Method}

Stimuli. The stimuli were sequences of 150 -msec tones generated by a Mallory Sonalert (Model SC 628) dc tone generator, which produced an almost sinusoidal waveform with a frequency of $2800 \mathrm{~Hz}$. The onset intervals ${ }^{2}$ between tones were varied and the sequences were presented in a cyclic fashion.

The subjects performed the following tasks:

First, they reproduced four single-interval sequences with intervals of $250,500,750$, and $1,000 \mathrm{msec}$.

Second, the subjects reproduced five two-interval sequences containing intervals of 250-1,000, 250-750, 250-500, 500-750, and $750-1,000 \mathrm{msec}$. Thus, the two-interval patterns comprised intervals forming ratios of $1: 4(.25), 1: 3(.33), 1: 2(.5), 2: 3$ (.66), and $3: 4(.75)$, respectively.

The third task involved the reproduction of six three-interval and six four-interval sequences. These sequences were the main focus of the experiment and were designed to invoke either a metrical or a nonmetrical interpretation. ${ }^{3}$ Table 1 shows the structure of each sequence in terms of the number of elements, the interval ratios, and the subdivisions of the beat intervals. ${ }^{4}$ Set 1 sequences are conducive to a metrical interpretation because (1) they can be subdivided into equal time intervals, and (2) the beat intervals are empty, filled with equal intervals, or filled with unequal intervals that relate as 2:1 or $3: 1$.

Set 2 sequences do not allow a metrical representation because either they cannot be subdivided into equal time intervals (Stimuli 1-4) or they contain beat intervals subdivided into unequal intervals that do not relate as 1:2 or 1:3 (Stimulus 5). Stimulus 6, although allowing a metrical interpretation, contains two $1,500-\mathrm{msec}$ beat intervals. Povel (1981) suggests that the preferred duration of a beat interval lies between approximately 250 and $1,500 \mathrm{msec}$.

The stimuli within each task were presented to subjects in a random order. Tasks 1 and 2 were included to provide a base measure with which to compare the reproductions of Task 3 stimuli, and to detect possible differences between musicians and nonmusicians.
Table 1

The Two Sets of Three- and Four-Interval Sequences Used in Experiment 1

\begin{tabular}{ccccc}
\hline & $\begin{array}{c}\text { Number } \\
\text { of } \\
\text { Stimulus }\end{array}$ & $\begin{array}{c}\text { Interval } \\
\text { Elements }\end{array}$ & $\begin{array}{c}\text { Subdivisions of } \\
\text { Reat Intervals }\end{array}$ \\
\cline { 4 - 6 } & & 1st Beat & 2nd Beat \\
\hline
\end{tabular}

1. $250-250-500$
2. $250-500-750$
3. $250-750-1,000$
4. $250-250-250-750$
5. $250-250-500-1,000$
6. $250-500-500-750$
Set 1: Metrical

$\begin{array}{llll}4 & 1: 1: 2 & 1: 1 & \text { empty } \\ 6 & 1: 2: 3 & 1: 2 & \text { empty } \\ 8 & 1: 3: 4 & 1: 3 & \text { empty } \\ 6 & 1: 1: 1: 3 & 1: 1: 1 & \text { empty } \\ 8 & 1: 1: 2: 4 & 1: 1: 2 & \text { empty } \\ 8 & 1: 2: 2: 3 & 2: 2 & 3: 1\end{array}$

Set 2: Nonmetrical

$\begin{array}{lrlll}\text { 1. } 250-250-750 & 5 & 1: 1: 3 & - & - \\ \text { 2. } 250-500-500 & 5 & 1: 2: 2 & - & - \\ \text { 3. } 250-500-1,000 & 7 & 1: 2: 4 & - & - \\ \text { 4. } 250-250-250-500 & 5 & 1: 1: 1: 2 & - & - \\ \text { 5. } 250-500-750-1,000 & 10 & 1: 2: 3: 4 & 2: 3 & 4: 1 \\ \text { 6. } 500-750-750-1,000 & 12 & 2: 3: 3: 4 & 3: 3 & 4: 2\end{array}$

Note-Only one period of each sequence is shown. Durations are in milliseconds.

Procedure. Subjects were instructed to listen to a tone sequence repeatedly presented through earphones and, when ready, to begin tapping a "practice key" (Honeywell Microswitch PK89133) with the right index finger in synchrony with the tones. When subjects thought that they could imitate the sequence, they began to reproduce the sequence on an identical second key, the "performance key." The first tap on the performance key stopped the presentation of the stimulus tones. Instead, each keytap produced a tone identical to that heard in stimulus generation. The stimulus and response phases, therefore, were perceptually compatible. Both stimulus generation and response recording were controlled by a PDP-11/10 computer operating in conjunction with a MDX microprocessor.

Subjects tapped the performance key until they had reproduced the sequence 17 times. There was no limit on the number of times subjects could attempt to imitate a sequence. Only the most accurate attempt was used for data analysis.

Data analysis. Of primary interest in the present study was a comparison of subjects' ability to imitate (Experiment 1 ) and produce (Experiment 2) temporal patterns containing varying duration ratios. In order to be able to compare performance across the various temporal patterns tested, we used a single measure of the precision with which the interval ratios in a pattern were imitated or produced. This measure, known as the Precision Index (Summers, Sargent, \& Hawkins, 1984), was based upon the ratio of each interval produced during one cycle of a timing pattern to the total duration of the cycle. Within each cycle of a temporal pattern, the absolute deviations between the ratios in the stimulus (expected ratios) and in the actual performance (observed ratios) were calculated. The absolute values of expected ratios minus observed ratios were then summed and a mean value for the block of trials was obtained. The Precision Index is always expressed as a positive value with more accurately performed timing patterns having an index value closer to zero. The use of a measure of relative time rather than absolute time allowed comparisons to be made between performance in the imitation task and performance in the production task (Experiment 2), in which subjects were free to choose the tempo of the produced sequences.

Subjects. Thirty-two volunteers from the Melbourne Conservatorium of Music and Melbourne University participated in the experiment. Sixteen were musically trained, having played an instrument for at least 5 years. 
Table 2

Mean and Standard Deviation of the Interval Ratios and the Precision Index in the Imitation of Two-Interval Sequences

\begin{tabular}{|c|c|c|c|c|c|c|c|c|c|c|c|}
\hline & & & & \multicolumn{4}{|c|}{ Musicians } & \multicolumn{4}{|c|}{ Nonmusicians } \\
\hline \multicolumn{4}{|c|}{ Stimulus } & \multicolumn{2}{|c|}{$t_{1} / t_{2}$} & \multicolumn{2}{|c|}{ Precision Index } & \multicolumn{2}{|c|}{$t_{1} / t_{2}$} & \multicolumn{2}{|c|}{ Precision Index } \\
\hline No. & $t_{1}$ & $t_{2}$ & $t_{1} / t_{2}$ & $M$ & $S D$ & $M$ & $S D$ & $M$ & $S D$ & $M$ & $S D$ \\
\hline 1 & 250 & 1,000 & .25 & .31 & .04 & .036 & .022 & .36 & .06 & .066 & .030 \\
\hline 2 & 250 & 750 & .33 & .39 & .06 & .035 & .023 & .41 & .06 & .045 & .022 \\
\hline 3 & 250 & 500 & .50 & .48 & .04 & .020 & .013 & .46 & .05 & .028 & .012 \\
\hline 4 & 500 & 750 & .66 & .52 & .06 & .059 & .023 & .54 & .15 & .072 & .028 \\
\hline 5 & 750 & 1,000 & .75 & $.61^{*}$ & .14 & .063 & .036 & $.71 *$ & .19 & .058 & .032 \\
\hline
\end{tabular}

Note-Durations are in milliseconds. ${ }^{*}$ These values are misleading, as they represent the average of contrary tendencies. This is reflected in high $S D$.

\section{Results}

The imitation results are based on 15 repetitions by the subjects, the first two imitations of each sequence having been excluded.

Examination of the performance of subjects in the single-interval task revealed no differences related to musical training. The 250-, 500-, 750-, and 1,000-msec intervals were reproduced with mean values of 255,504 , 744 , and $972 \mathrm{msec}$ and standard deviations of $14,18,43$, and $41 \mathrm{msec}$, respectively.

Table 2 presents the imitation results for the twointerval sequences separately for musicians and nonmusicians in terms of the mean interval ratio of the imitations and the Precision Index. Intersubject differences are shown by the standard deviations. The Precision Index scores were subjected to an analysis of variance with group and pattern as factors. There were significant main effects of group $[F(1,30)=6.59, p<.02]$ and pattern $[F(4,120)=15.19, p<.001]$. A Newman-Keuls analysis revealed that the interval ratio 1:2 (Stimulus 3) was more accurately reproduced than any other interval ratio $(p<.01)$. The interval ratio $1: 3$ was more accurately imitated than the 2:3 and 3:4 ratios $(p<.01)$, while reproduction of the $1: 4$ ratio was also superior to the $2: 3$ ratio $(p<.01)$.

As can be seen in Table 2, stimuli with interval ratios smaller than .5 were consistently reproduced with interval ratios approaching .5. A similar tendency was evident in the stimuli with intervals greater than .5, except for some subjects who showed a tendency toward 1 (equal intervals) in their imitation of the .75 pattern.

The mean Precision Index scores for the metrical and nonmetrical sequences of Task 3 are shown in Figure 1 for musicians and nonmusicians separately. Subject and item analyses were performed on the Precision Index data, and the procedure of calculating minimum $F^{\prime}$ was also employed (Clark, 1973). In the analysis of variance, the main effect of condition was significant [minimum $\left.F^{\prime}(1,32)=10.66, p<.01\right]$. However, the magnitude of the condition effect was greater in the musician group (see Figure 1), resulting in a tendency for an interaction between group and condition, which was significant by subjects $\left[F_{1}(1,30)=4.45, p<.05\right]$, though not by items $\left[F_{2}(1,30)=3.45\right]$.
The imitation responses are summarized separately for the patterns in the metrical (Table 3) and nonmetrical conditions (Table 4). For each stimulus pattern, the mean and standard deviation of the Precision Index is given, and interval relations in the stimuli and responses are shown as the ratio of the longest interval in the sequence.

For the metrical condition, Sequences 1, 2, 4, and 5 were well imitated by both groups of subjects. Sequences 3 (1:3:4) and 6 (1:1:2:4), however, were imitated less accurately by nonmusicians than by musicians. Nonmusicians showed a tendency to shorten the last interval in these patterns.

Reproductions of the patterns in the nonmetrical condition were similar for musicians and nonmusicians, with the exception of Sequence 2 (1:2:4), which was more accurately imitated by musicians. For this pattern, nonmusicians showed a greater tendency toward shortening the last interval than did musicians. In general, imitations of nonmetric sequences were characterized by large distortions that seemed to reflect, in some cases, attempts by subjects to fit the presented sequence into a beat-based

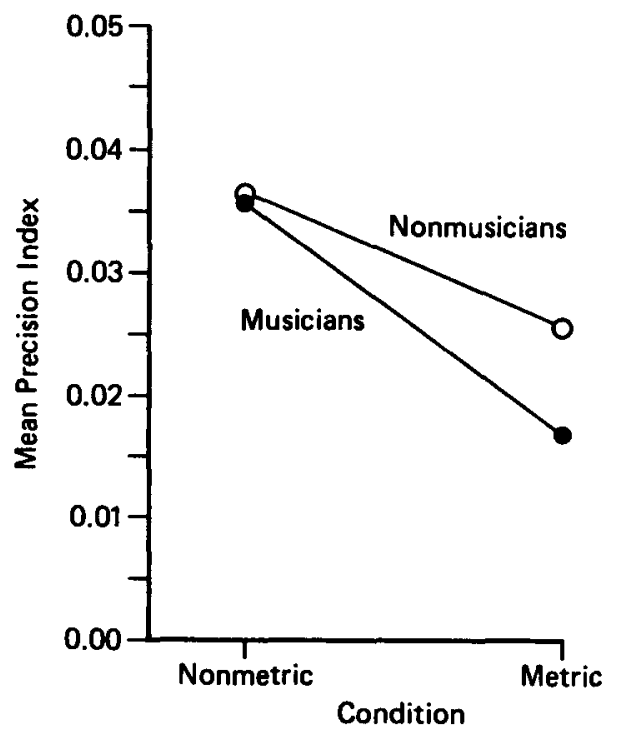

Figure 1. Mean Precision Index scores for musicians and nonmusicians in the nonmetric and metric conditions in Experiment 1. 
structure. This strategy was particularly evident in Sequences $3(1: 2: 2)$ and $4(1: 1: 1: 2)$, which subjects, by lengthening the last interval, tended to reproduce as $1: 2: 3$ and $1: 1: 1: 3$, respectively. The opposite tendency of shortening the last interval was apparent in Sequence 1 (1:1:3), although some subjects in the musician group tended to reproduce this pattern as $1: 1: 4$. The two remaining nonmetrical patterns, 1:2:3:4 and 2:3:3:4, were characterized by exceptionally high interval ratio standard deviations, indicating that subjects found these patterns extremely difficult to reproduce.

\section{Discussion}

The results for the two-interval sequences are similar to those obtained by Povel (1981). Only the pattern with intervals relating as 1:2 was accurately imitated. Imitation of all other patterns showed a general tendency toward an interval relation of 1:2. These findings add further support to the view that such sequences are internally represented as unstructured groups of tones strongly influenced by the tendency to conceptualize duration differences in a 1:2 relation (Fraisse, 1956; Povel, 1981).

For the three- and four-interval sequences, patterns allowing a metrical representation were reproduced more accurately than nonmetrically represented patterns, lending support to the notion of an internal timing structure, or clock, that is used to specify the temporal structure of a presented sequence (Essens \& Povel, 1985; Povel, 1981). Furthermore, the distinction between metrical and

Table 3

Mean Interval Ratios and Precision Index Scores for Sequences in the Metric Condition

\begin{tabular}{lcccccc}
\hline & \multicolumn{3}{c}{ Musicians } & \multicolumn{3}{c}{ Nonmusicians } \\
\cline { 2 - 7 } Interval Pair & $t_{1} / t_{\mathbf{3}}$ & $\boldsymbol{t}_{\mathbf{2}} / \boldsymbol{t}_{\mathbf{3}}$ & PI & $\boldsymbol{t}_{\mathbf{1}} / t_{\mathbf{3}}$ & $\boldsymbol{t}_{\mathbf{2}} / \boldsymbol{t}_{\mathbf{3}}$ & PI \\
\hline Sequence 1 & .50 & .50 & .000 & .50 & .50 & .000 \\
Imitation & .46 & .48 & .014 & .45 & .46 & .019 \\
SD & .03 & .02 & .007 & .04 & .04 & .010 \\
Sequence 2 & .33 & .66 & .000 & .33 & .66 & .000 \\
Imitation & .32 & .69 & .022 & .35 & .72 & .028 \\
SD & .07 & .08 & .009 & .04 & .16 & .018 \\
Sequence 3 & .25 & .75 & .000 & .25 & .75 & .000 \\
Imitation & .27 & .74 & .022 & .32 & .79 & .038 \\
SD & .04 & .10 & .012 & .06 & .21 & .022
\end{tabular}

\begin{tabular}{lcccccccc} 
& $t_{1} / t_{4}$ & $t_{2} / t_{4}$ & $t_{3} / t_{4}$ & PI & $t_{1} / t_{4}$ & $t_{2} / t_{4}$ & $t_{3} / t_{4}$ & PI \\
\cline { 2 - 8 } Sequence 4 & .33 & .33 & .33 & .000 & .33 & .33 & .33 & .000 \\
Imitation & .33 & .32 & .35 & .013 & .35 & .34 & .37 & .016 \\
$S D$ & .04 & .03 & .04 & .006 & .04 & .04 & .04 & .006 \\
Sequence 5 & .25 & .25 & .50 & .000 & .25 & .25 & .50 & .000 \\
Imitation & .26 & .27 & .56 & .015 & .30 & .31 & .67 & .032 \\
SD & .05 & .05 & .08 & .013 & .05 & .06 & .16 & .022 \\
Sequence 6 & .33 & .66 & .66 & .000 & .33 & .66 & .66 & .000 \\
Imitation & .30 & .65 & .66 & .014 & .33 & .68 & .69 & .017 \\
SD & .04 & .05 & .11 & .009 & .10 & .11 & .08 & .010 \\
\hline
\end{tabular}

Note-Sequence $1, t_{1}=250, t_{2}=250, t_{3}=500$; Sequence $2, t_{1}=250$, $t_{2}=500, t_{3}=750$; Sequence 3, $t_{1}=250, t_{2}=750, t_{3}=1,000$; Sequence 4, $t_{1}=250, t_{2}=250, t_{3}=250, t_{4}=750 ;$ Sequence $5, t_{1}=250, t_{2}=250$, $t_{3}=500, t_{4}=1,000 ;$ Sequence $6, t_{1}=250, t_{2}=500, t_{3}=500, t_{4}=750$. PI $=$ Precision Index.
Table 4

Mean Interval Ratios and Precision Index Scores for Sequences in the Nonmetric Condition

\begin{tabular}{|c|c|c|c|c|c|c|}
\hline \multirow[b]{2}{*}{ Interval Pair } & \multicolumn{3}{|c|}{ Musicians } & \multicolumn{3}{|c|}{ Nonmusicians } \\
\hline & $t_{1} / t_{3}$ & $t_{2} / t_{3}$ & PI & $t_{1} / t_{3}$ & $t_{2} / t_{3}$ & PI \\
\hline $\begin{array}{l}\text { Sequence } 1 \\
\text { Imitation } \\
S D\end{array}$ & $\begin{array}{l}.33 \\
.35 * \\
.09\end{array}$ & $\begin{array}{l}.33 \\
.36^{*} \\
.08\end{array}$ & $\begin{array}{l}.000 \\
.035 \\
.017\end{array}$ & $\begin{array}{l}.33 \\
.37 \\
.05\end{array}$ & $\begin{array}{l}.33 \\
.37 \\
.06\end{array}$ & $\begin{array}{l}.000 \\
.027 \\
.013\end{array}$ \\
\hline $\begin{array}{l}\text { Sequence } 2 \\
\text { Imitation } \\
S D\end{array}$ & $\begin{array}{l}.50 \\
.38 \\
.10\end{array}$ & $\begin{array}{r}1.00 \\
.82 \\
.23\end{array}$ & $\begin{array}{l}.000 \\
.055 \\
.025\end{array}$ & $\begin{array}{l}.50 \\
.38 \\
.06\end{array}$ & $\begin{array}{r}1.00 \\
.82 \\
.19\end{array}$ & $\begin{array}{l}.000 \\
.048 \\
.024\end{array}$ \\
\hline $\begin{array}{l}\text { Sequence } 3 \\
\text { Imitation } \\
S D\end{array}$ & $\begin{array}{l}.25 \\
.26 \\
.04\end{array}$ & $\begin{array}{l}.50 \\
.56 \\
.11\end{array}$ & $\begin{array}{l}.000 \\
.030 \\
.012\end{array}$ & $\begin{array}{l}.25 \\
.31 \\
.04\end{array}$ & $\begin{array}{l}.50 \\
.66 \\
.12\end{array}$ & $\begin{array}{l}.000 \\
.045 \\
.018\end{array}$ \\
\hline
\end{tabular}

\begin{tabular}{lcccccccc} 
& $t_{1} / t_{4}$ & $t_{2} / t_{4}$ & $t_{3} / t_{4}$ & PI & $t_{1} / t_{4}$ & $t_{2} / t_{4}$ & $t_{3} / t_{4}$ & PI \\
Sequence 4 & .50 & .50 & .50 & .000 & .50 & .50 & .50 & .000 \\
Imitation & .39 & .39 & .42 & .033 & .38 & .38 & .40 & .034 \\
$S D$ & .06 & .07 & .09 & .016 & .05 & .05 & .04 & .015 \\
Sequence 5 & .25 & .50 & .75 & .000 & .25 & .50 & .75 & .000 \\
Imitation & .30 & .62 & .90 & .030 & .31 & .62 & .90 & .032 \\
$S D$ & .05 & .14 & .24 & .017 & .05 & .11 & .15 & .011 \\
Sequence 6 & .50 & .75 & .75 & .000 & .50 & .75 & .75 & .000 \\
Imitation & .43 & .77 & .78 & .031 & .48 & .82 & .82 & .031 \\
$S D$ & .11 & .17 & .20 & .016 & .13 & .17 & .14 & .010 \\
\hline
\end{tabular}

Note-Sequence $1, t_{1}=250, t_{2}=250, t_{3}=750$; Sequence $2, t_{1}=250$, $t_{2}=500, t_{3}=500 ;$ Sequence $3, t_{1}=250, t_{2}=500, t_{3}=1,000$; Sequence 4, $t_{1}=250, t_{2}=250, t_{3}=250, t_{4}=500$; Sequence 5, $t_{1}=250, t_{2}=500$, $t_{3}=750, t_{4}=1,000 ;$ Sequence $6, t_{1}=500, t_{2}=750, t_{3}=750, t_{4}=1,000$. $\mathrm{PI}=$ Precision Index. ${ }^{*}$ These values are unreliable, as they represent the average of contrary tendencies to reproduce the pattern as $1: 1: 2$ or 1:1:4. This is reflected in high precision index.

nonmetrical coding was obtained with patterns considerably more complex than those used in previous studies. Both Povel (1981) and Essens and Povel (1985) used relatively simple sequences, which comprised only two durations, regardless of the number of intervals, a short duration and a long duration. In the present experiment, sequences contained two, three, or four different durations.

Some comment should be made regarding the imitation responses of musicians and nonmusicians. Although the two groups exhibited similar levels of accuracy in the reproduction of 9 of the 12 patterns tested, nonmusicians were much less accurate on the remaining three patterns $(1: 3: 4,1: 2: 4,1: 1: 2: 4)$. The difference between the two groups in the imitation of these three patterns appears to be due to the inability of musically untrained subjects to accurately imitate 1,000 -msec intervals. Nonmusicians showed a greater underestimation of the 1,000 -msec interval than the musicians in the imitation of single intervals (963 vs. $981 \mathrm{msec}$ ) and the two-interval sequence (250-1,000 msec; see Table 1).

\section{EXPERIMENT 2}

The previous experiment examined the reproduction of temporal patterns and obtained evidence in support of the notion of an internal structure or clock on which subjects 
attempt to map presented temporal patterns. In Experiment 2 , we sought further evidence for the beat-based coding of temporal sequences through the use of a production task. Sternberg and Knoll (1984) have proposed that although imitation and production tasks involve different encoding processes, they make use of a common internal representation and response-generation process. If a metrical representation is of universal origin (Povel, 1981), then imitation and production tasks should give similar results. That is, patterns allowing a metrical interpretation should be imitated and produced more accurately than those that do not.

\section{Method}

The experiment was divided into two phases: a training phase and an experimental phase.

Training phase. The training phase involved an imitation task identical to that used in Experiment 1. Subjects imitated four singleinterval sequences with intervals of $250,500,750$, and $1,000 \mathrm{msec}$. Practice on each sequence was continued until the subjects exhibited reasonably aecurate and stable performance. Immediately following the final imitation trial, the subjects were tested on their ability to spontaneously produce the single-interval sequences. The procedure for the production task was similar to that used for the imitation task, with the exception that no stimulus tones were presented. Subjects practiced each sequence by tapping the practice key for as long as they wished, before moving to the performance key. Each keytap on both the practice and performance keys produced a 150 -msec tone of $2800 \mathrm{~Hz}$. Subjects tapped the performance key until they had produced the sequence 17 times. There was no limit on the number of times subjects could attempt to produce a sequence.

The training phase was included to provide subjects with an overall temporal framework for the production of the sequences in the experimental phase.

Experimental phase. The experimental phase involved a production task identical to that used for the spontaneous production of single intervals. Subjects were told that they were to tap a specific pattern containing two, three, or four intervals. Patterns to be produced were presented as a sequence of numbers on a card. The subjects were instructed that the number 1 represented the shortest interval ( $250 \mathrm{msec})$ they had received during training on single intervals. The other intervals in a sequence were then expressed as a ratio of the reference interval. For example, the numbers $1: 2: 3$ informed subjects that they were to produce a sequence of three intervals, with the second interval twice the length of the first and the third interval three times the length of Interval 1. Pilot testing had shown that the use of a reference interval made the task requirements easier to understand and minimized the tempo differences between subjects.

The subjects performed the following tasks: First, they produced three two-interval sequences with interval ratios of $1: 4(.25), 1: 3$ (.33), and 1:2 (.50). The second task involved the production of six three-interval and six four-interval sequences. The structure of the sequences, in terms of interval ratios, was identical to that of Experiment 1 (see Table 1), with one exception. Pilot testing had revealed that subjects had great difficulty in producing the nonmetrical pattern 2:3:3:4. In Experiment 2, this pattern was replaced with the nonmetrical pattern $1: 1: 1: 4$.

The subjects were requested to repetitively tap each pattern 17 times at their own tempos. Extinction of the response tone signaled the end of a trial. Within each task, the order of presentation of sequences was randomized across subjects.

Subjects. Twenty-eight subjects from the Melbourne Conservatorium of Music and Melbourne University participated in the ex- periment. Fourteen were musically trained. None had participated in Experiment 1.

\section{Results}

As in Experiment 1, for each sequence only the most accurate attempt was used for data analysis, and the results are based on 15 repetitions by the subjects, the first two repetitions having been excluded.

Training phase. Table 5 shows the mean and standard deviation of the intervals produced by subjects for the single-interval sequences separately for the imitation and production tasks. Also shown is the mean and standard deviation of individual standard deviations as a measure of intrasubject variability. As there were no differences related to musical training in either task, the data of both groups are combined.

The results for the imitation task are similar to those obtained in Experiment 1. Spontaneous production of the single-interval sequences, in contrast, was marked by high intersubject variability. However, intrasubject variability was low and comparable to that evident in the imitation task.

Experimental phase. The results for the two-interval sequences are summarized in Table 6 separately for the musically trained and untrained subjects. The interval ratios of $1: 3(.33)$ and $1: 4(.25)$ were accurately produced by musicians. The interval ratio 1:2 (.50), however, was poorly produced by these subjects, showing a strong tendency in the direction of greater distinction of the two intervals. The responses of nonmusicians were charac-

Table 5

Mean and Standard Deviations of Responses and Individual Standard Deviations in the Reproduction and Production of Single Intervals

\begin{tabular}{|c|c|c|c|c|c|}
\hline \multirow[b]{2}{*}{ Interval } & & \multicolumn{2}{|c|}{ Continuation } & \multicolumn{2}{|c|}{ Production } \\
\hline & & $\begin{array}{c}\text { Reproduced } \\
\text { Duration }\end{array}$ & $S D^{*}$ & $\begin{array}{l}\text { Produced } \\
\text { Duration }\end{array}$ & $S D^{*}$ \\
\hline 250 & $\begin{array}{c}M \\
S D\end{array}$ & $\begin{array}{r}250.70 \\
5.30\end{array}$ & $\begin{array}{l}9.14 \\
2.66\end{array}$ & $\begin{array}{r}269.86 \\
71.96\end{array}$ & $\begin{array}{r}10.75 \\
5.30\end{array}$ \\
\hline 500 & $\begin{array}{c}M \\
S D\end{array}$ & $\begin{array}{r}500.21 \\
12.76\end{array}$ & $\begin{array}{r}15.50 \\
4.63\end{array}$ & $\begin{array}{r}472.82 \\
94.59\end{array}$ & $\begin{array}{r}17.79 \\
6.09\end{array}$ \\
\hline 750 & $\begin{array}{c}M \\
S D\end{array}$ & $\begin{array}{r}740.14 \\
24.08\end{array}$ & $\begin{array}{r}23.29 \\
6.85\end{array}$ & $\begin{array}{l}722.39 \\
109.98\end{array}$ & $\begin{array}{r}27.43 \\
7.77\end{array}$ \\
\hline 1,000 & $\begin{array}{c}M \\
S D \\
\end{array}$ & $\begin{array}{r}993.79 \\
41.82 \\
\end{array}$ & $\begin{array}{l}32.79 \\
10.34 \\
\end{array}$ & $\begin{array}{l}941.61 \\
126.96 \\
\end{array}$ & $\begin{array}{l}33.79 \\
11.61 \\
\end{array}$ \\
\hline
\end{tabular}

Note-Durations are in milliseconds. *Standard deviation of individual standard deviations.

Table 6

Mean and Standard Deviation of the Interval Ratios and the Precision Index in the Production of Two-Interval Sequences

\begin{tabular}{|c|c|c|c|c|c|c|c|c|}
\hline \multirow[b]{3}{*}{ Sequence } & \multicolumn{4}{|c|}{ Musicians } & \multicolumn{4}{|c|}{ Nonmusicians } \\
\hline & \multicolumn{2}{|c|}{$t_{1} / t_{2}$} & \multicolumn{2}{|c|}{ Precision Index } & \multicolumn{2}{|c|}{$t_{1} / t_{2}$} & \multicolumn{2}{|c|}{ Precision Index } \\
\hline & $M$ & $S D$ & $M$ & $S D$ & $M$ & $S D$ & $M$ & $S D$ \\
\hline & .25 & .0 & .028 & .01 & .24 & .1 & 051 & 9 \\
\hline & .34 & .06 & & & .30 & .1 & & \\
\hline $1: 2(.50)$ & .43 & .08 & .040 & .035 & .42 & .10 & .048 & .048 \\
\hline
\end{tabular}


terized by high intersubject variability and a general tendency to exaggerate the difference between short and long durations. This tendency was particularly evident in the production of the 1:2 pattern. The Precision Index scores were subjected to an analysis of variance with group and pattern as factors. Only the main effect of group was significant $[F(1,26)=5.26, p<.04]$.

The Precision Index scores averaged over patterns in the metrical and nonmetrical conditions are shown in Figure 2 for musicians and nonmusicians separately. An analysis of variance performed on the Precision Index data gave a significant group effect $\left[\min F^{\prime}(1,36)=18.63\right.$, $p<.001]$ but no condition effect or group $\times$ condition interaction.

The interval relations produced and the Precision Index for each pattern in the metric and nonmetric conditions are shown in Tables 7 and 8 , respectively.

Three general findings emerge from examination of individual patterns. First, musicians' performance was superior to nonmusicians' across all the sequences tested. Second, for both groups, the structure of a pattern, in terms of whether it allowed a metrical or nonmetrical interpfetation, had little influence on production accuracy. Third, subjects' productions seemed to be dominated by two organizing principles: distinction and assimilation. Although these two tendencies were evident in the responses of both groups, they were more pronounced, especially distinction, in the nonmusician group. Distinction occurred whenever the reference interval ( 1 on the stimulus card) was followed by a longer interval (i.e., 1:2, $1: 3$, or 1:4). Furthermore, the amount of differentiation between a particular short-long ratio was fairly consistent across the patterns in which that interval ratio occurred. The interval ratio 1:2 appeared in 8 of the 12 se-

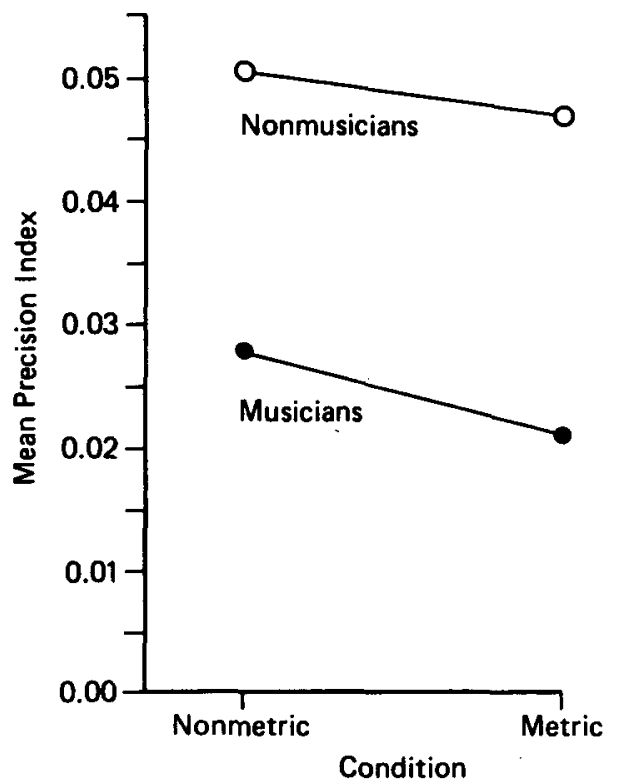

Figure 2. Mean Precision Index scores for musicians and nonmusicians in the nonmetric and metric conditions in Experiment 2.
Table 7

Mean Interval Ratios and Precision Index Scores for Sequences in the Metric Condition

\begin{tabular}{lcccccc}
\hline & \multicolumn{3}{c}{ Musicians } & \multicolumn{3}{c}{ Nonmusicians } \\
\cline { 2 - 6 } \cline { 5 - 7 } Interval Pair & $t_{1} / t_{3}$ & $t_{2} / t_{3}$ & PI & $t_{1} / t_{3}$ & $t_{2} / t_{3}$ & PI \\
\hline Sequence 1 & .50 & .50 & .000 & .50 & .50 & .000 \\
Production & .43 & .44 & .027 & .35 & .43 & .077 \\
$S D$ & .06 & .05 & .022 & .11 & .27 & .053 \\
Sequence 2 & .33 & .66 & .000 & .33 & .66 & .000 \\
Production & .31 & .72 & .028 & .27 & .78 & .047 \\
SD & .06 & .10 & .015 & .10 & .14 & .020 \\
Sequence 3 & .25 & .75 & .000 & .25 & .75 & .000 \\
Production & .26 & .80 & .023 & .21 & .80 & .040 \\
SD & .05 & .10 & .014 & .06 & .15 & .015
\end{tabular}

\begin{tabular}{lcccccccc} 
& $t_{1} / t_{4}$ & $t_{2} / t_{4}$ & $t_{3} / t_{4}$ & PI & $t_{1} / t_{4}$ & $t_{2} / t_{4}$ & $t_{3} / t_{4}$ & PI \\
\cline { 2 - 8 } Sequence 4 & .33 & .33 & .33 & .000 & .33 & .33 & .33 & .000 \\
Production & .31 & .31 & .33 & .018 & .26 & .26 & .27 & .041 \\
$S D$ & .05 & .05 & .05 & .013 & .08 & .07 & .07 & .027 \\
Sequence 5 & .25 & .25 & .50 & .000 & .25 & .25 & .50 & .000 \\
Production & .23 & .24 & .53 & .014 & .21 & .23 & .64 & .041 \\
SD & .03 & .02 & .05 & .008 & .06 & .10 & .15 & .020 \\
Sequence 6 & .33 & .66 & .66 & .000 & .33 & .66 & .66 & .000 \\
Production & .29 & .65 & .65 & .017 & .22 & .63 & .66 & .037 \\
SD & .05 & .08 & .06 & .015 & .07 & .18 & .18 & .014 \\
\hline
\end{tabular}

Note-Sequence 1, 1:1:2; Sequence 2, 1:2:3; Sequence 3, 1:3:4; Sequence 4, 1:1:1:3; Sequence 5, 1:1:2:4; Sequence 6, 1:2:2:3. PI = Precision Index.

quences tested, with a mean ratio of $3: 13$ for nonmusicians and $2: 37$ for musicians. For the interval ratio $1: 3$, which occurred in three patterns, the mean was 3.99 for nonmusicians and 3.10 for musicians. Finally, the 1:4 ratio in the pattern $1: 1: 1: 4$ was produced as 4.59 by nonmusicians and as 4.29 by musicians.

For the long intervals in a pattern (i.e., intervals longer than the reference interval), the opposite tendency toward assimilation was evident. For example, in the threeinterval sequences $1: 2: 3,1: 2: 4$, and 1:3:4, with the ratio between the second and third intervals being $.66, .50$, and .75 , nonmusicians produced ratios of $.78, .64$, and .80 and musicians ratios of $.72, .59$, and .80 . However, the fact that subjects never produced completely isochronic durations shows that they were able to distinguish between the long intervals.

\section{Discussion}

In this experiment, no difference was found in the accuracy with which subjects produced patterns allowing a metrical interpretation and those that do not. The results appear to be consistent with the previous findings of Fraisse $(1946,1956,1978)$. In a series of spontaneous tapping experiments, Fraisse found that subjects basically used only two types of duration: short durations (shorter than $400 \mathrm{msec}$ ) and long durations (longer than $400 \mathrm{msec}$ ). Within each type there was assimilation of durations, whereas between the two types there was a tendency to exaggerate time differences. These two organizing tendencies were clearly evident in the present experiment. The reference interval produced by subjects 
Table 8

Mean Interval Ratios and Precision Index Scores for Sequences in the Nonmetric Condition

\begin{tabular}{|c|c|c|c|c|c|c|c|c|}
\hline \multirow[b]{2}{*}{ Interval Pair } & \multicolumn{4}{|c|}{ Musicians } & \multicolumn{4}{|c|}{ Nonmusicians } \\
\hline & $t_{1} / t_{3}$ & & $t_{2} / t_{3}$ & $\overline{\mathrm{PI}}$ & $\overline{t_{1} / t_{3}}$ & & $t_{2} / t_{3}$ & $\overline{\text { PI }}$ \\
\hline $\begin{array}{l}\text { Sequence } 1 \\
\text { Production } \\
\text { SD }\end{array}$ & $\begin{array}{l}.33 \\
.30 \\
.06\end{array}$ & & $\begin{array}{l}.33 \\
.33 \\
.11\end{array}$ & $\begin{array}{l}.000 \\
.031 \\
.017\end{array}$ & $\begin{array}{l}.33 \\
.27 \\
.11\end{array}$ & & $\begin{array}{l}.33 \\
.28 \\
.16\end{array}$ & $\begin{array}{l}.000 \\
.062 \\
.037\end{array}$ \\
\hline $\begin{array}{l}\text { Sequence } 2 \\
\text { Production } \\
S D\end{array}$ & $\begin{array}{l}.50 \\
.39 \\
.08\end{array}$ & & $\begin{array}{r}1.00 \\
.88 \\
.14\end{array}$ & $\begin{array}{l}.000 \\
.035 \\
.030\end{array}$ & $\begin{array}{l}.50 \\
.30 \\
.08\end{array}$ & & $\begin{array}{r}1.00 \\
.88 \\
.18\end{array}$ & $\begin{array}{l}.000 \\
.057 \\
.022\end{array}$ \\
\hline $\begin{array}{l}\text { Sequence } 3 \\
\text { Production } \\
\text { SD }\end{array}$ & $\begin{array}{l}.25 \\
.25 \\
.04\end{array}$ & & $\begin{array}{l}.50 \\
.59 \\
.04\end{array}$ & $\begin{array}{l}.000 \\
.026 \\
.011\end{array}$ & $\begin{array}{l}.25 \\
.21 \\
.08\end{array}$ & & $\begin{array}{l}.50 \\
.64 \\
.20\end{array}$ & $\begin{array}{l}.000 \\
.049 \\
.031\end{array}$ \\
\hline$S D$ & $t_{1} / t_{4}$ & $t_{2} / t_{4}$ & $t_{3} / t_{4}$ & PI & $t_{1} / t_{4}$ & $t_{2} / t_{4}$ & $t_{3} / t_{4}$ & $\mathrm{PI}$ \\
\hline $\begin{array}{l}\text { Sequence } 4 \\
\text { Production } \\
S D\end{array}$ & $\begin{array}{l}.50 \\
.39 \\
.07\end{array}$ & $\begin{array}{l}.50 \\
.39 \\
.06\end{array}$ & $\begin{array}{l}.50 \\
.40 \\
.06\end{array}$ & $\begin{array}{l}.000 \\
.032 \\
.018\end{array}$ & $\begin{array}{l}.50 \\
.37 \\
.21\end{array}$ & $\begin{array}{l}.50 \\
.37 \\
.20\end{array}$ & $\begin{array}{l}.50 \\
.37 \\
.20\end{array}$ & $\begin{array}{l}.000 \\
.061 \\
.030\end{array}$ \\
\hline $\begin{array}{l}\text { Sequence } 5 \\
\text { Production } \\
S D\end{array}$ & $\begin{array}{l}.25 \\
.25 \\
.06\end{array}$ & $\begin{array}{l}.50 \\
.61 \\
.12\end{array}$ & $\begin{array}{l}.75 \\
.83 \\
.17\end{array}$ & $\begin{array}{l}.000 \\
.025 \\
.015\end{array}$ & $\begin{array}{l}.25 \\
.19 \\
.06\end{array}$ & $\begin{array}{l}.50 \\
.66 \\
.19\end{array}$ & $\begin{array}{l}.75 \\
.83 \\
.20\end{array}$ & $\begin{array}{l}.000 \\
.040 \\
.017\end{array}$ \\
\hline $\begin{array}{l}\text { Sequence } 6 \\
\text { Production } \\
S D\end{array}$ & $\begin{array}{l}.25 \\
.23 \\
.04\end{array}$ & $\begin{array}{l}.25 \\
.22 \\
.04\end{array}$ & $\begin{array}{l}.25 \\
.23 \\
.03 \\
\end{array}$ & $\begin{array}{l}.000 \\
.019 \\
.017 \\
\end{array}$ & $\begin{array}{l}.25 \\
.21 \\
.06 \\
\end{array}$ & $\begin{array}{l}.25 \\
.21 \\
.06 \\
\end{array}$ & $\begin{array}{l}.25 \\
.22 \\
.06 \\
\end{array}$ & $\begin{array}{l}.000 \\
.035 \\
.018 \\
\end{array}$ \\
\hline
\end{tabular}

Note-Sequence 1, 1:1:3; Sequence 2, 1:2:2; Sequence 3, 1:2:4; Sequence $4,1: 1: 1: 2$; Sequence $5,1: 2: 3: 4$; Sequence $6,1: 1: 1: 4$. PI $=$ Precision Index.

averaged across patterns was 235 msec and the long intervals were all greater than $400 \mathrm{msec}$. Subjects showed a strong tendency to exaggerate the difference between the reference interval and longer intervals and to reduce the difference between successive long durations. The distinction tendency was particularly marked in the productions of musically untrained subjects.

\section{GENERAL DISCUSSION}

Essens and Povel (1985) have distinguished between two types of representations of temporal patterns: one metrical and the other nonmetrical. Whether or not a metrical interpretation is evoked depends on the structural characteristics of the presented pattern. The present results, however, suggest that the task a person is required to perform may also determine if an internal clock is generated.

Our data, however, are also consistent with the view of Kolers and Brewster (1985) that "people develop, not a memory trace of a time interval, but a strategy with which to approach the task" (p. 166). Listening to a sequence of tones and then synchronizing with the pattern in the induction phase of the imitation task used in Experiment 1 may be conducive to the identification of a recurrent beat. The application of a beat-based coding scheme in the imitation task may represent a strategy acquired either through musical training or by passive exposure to music. The finding that nonmusicians were not able to find the recurrent beat in the metrical patterns 250-750-1,000 and 250-250-500-1,000 suggests that a beat-based coding strategy was less well developed in these subjects.

The production task, in contrast, was a task unfamiliar to both groups of subjects. As a consequence, subjects reverted to a more primitive timing strategy based on the organizing principles of distinction and assimilation. It is possible, however, that the method of sequence presentation used in the production task discouraged subjects from attempting to identify and produce a recurrent beat. By defining intervals in a pattern relative to a reference interval, we may have encouraged subjects to extrapolate the longer durations by counting out multiples of the reference interval. The superior performance of musicians in the production task may reflect, therefore, a more efficient application of a counting strategy by these subjects. Although a number of subjects in both groups did report using a counting strategy, no obvious difference in performance between counters and noncounters was evident.

The use of different strategies in the performance of different timing tasks may also explain the results obtained by Smith (1983). She found that although musicians' reproductions of drum rhythms suggested an organization using the beat as a temporal framework, their responses in a perceptual judgment task reflected an organization based on temporal proximity.

The question of whether differences in performance obtained across different pattern structures, tasks, or modalities (Kolers \& Brewster, 1985) reflect either the use of different internal representations or different strategies is clearly an issue that must be addressed in future research.

\section{REFERENCES}

CLARK, H. H. (1973). The language-as-fixed-effect fallacy: A critique of language statistics in psychological research. Journal of Verbal Learning \& Verbal Behavior, 12, 335-359.

Essens, P. J., \& PoveL, D. J. (1985). Metrical and nonmetrical representations of temporal patterns. Perception \& Psychophysics, 37, 1-7.

Fraisse, P. (1946). Contribution à l'étude du rhythme en tant que forme temporelle. Journal de Psychologie Normale et Pathologique, 39, 283-304.

FraIsSE, P. (1956). Les structures rhythmiques. Louvain: Publications Universitaires de Louvain.

Fraisse, P. (1978). Time and rhythm perception. In E. C. Carterette \& M. P. Friedman (Eds.), Handbook of perception (Vol. 8, pp. 203254). New York: Academic Press.

Greeno, J. G., \& Simon, H. A. (1974). Processes for sequence production. Psychological Review, 81, 187-198.

JoNEs, M. R. (1978). Auditory patterns: Studies in the perception of structure. In E. C. Carterette \& M. P. Friedman (Eds.), Handbook of perception (Vol. 8, pp. 255-288). New York: Academic Press.

Kolers, P. A., \& Brewster, J. M. (1985). Rhythms and responses. Journal of Experimental Psychology: Human Perception \& Performance, 11, 150-167.

Longuet-Higarns, H. C., LeE, C. S. (1982). The perception of musical rhythms. Perception, 11, 115-128.

MarTin, J. G. (1972). Rhythmic (hierarchical) versus serial structure in speech and other behavior. Psychological Review, 79, 487-509.

Povel, D. J. (1981). Internal representation of simple temporal patterns. Journal of Experimental Psychology: Human Perception \& Performance, 7, 3-18.

Povel, D. J. (1984). A theoretical framework for rhythm perception. Psychological Research, 45, 315-337. 
Povel, D. J., \& Essens, P. J. (1985). Perception of temporal patterns. Music Perception, 2, 411-440.

SMITH, J. (1983). Reproduction and representation of musical rhythms: The effects of musical skill. In D. R. Rogers \& J. A. Sloboda (Eds.), The acquisition of symbolic skills. New York: Plenum Press.

StEEdMan, M. J. (1977). The perception of musical rhythm and metre. Perception, 6, 555-569.

SternberG, S., \& KNOLL, R. L. (1984). Perception, production and imitation of time ratios by skilled musicians. In J. Gibbon \& L. Allen (Eds.), Timing and time perception (Vol. 423). New York: Annals of the New York Academy of Sciences.

Summers, J. J., SARGent, G. I., \& HaWkins, S. R. (1984). Rhythm and the timing of movement sequences. Psychological Research, 46, 107-119.

VORBERG, D., \& HAMBUCH, R. (1978). On the temporal control of rhythmic performance. In J. Requin (Ed.), Attention and performance (Vol. 7, pp. 535-555). Hillsdale, NJ: Erlbaum.

\section{NOTES}

1. In this study, we are concerned with the general question of how people perceive and produce temporal sequences and not with the specific question of perceiving and playing music. We did not, therefore, restrict the patterns tested only to those occurring in music. Within this framework, the comparison between musicians and nonmusicians was seen as a comparison between skilled (individuals with special task-related experience and years of practice) and unskilled performers.

2. Throughout this article, the term interval is used to refer to the interval between onsets of adjacent tones.

3. Subjects actually reproduced eight three-interval and eight fourinterval sequences. For the present paper, however, we have included only those sequences having structures that allow either metrical or nonmetrical interpretations as defined by Povel (1981) and Essens and Povel (1985).

4. The term beat interval is used as synonymous with the terms grid interval (Povel, 1984) and metrical unit (Essens \& Povel, 1985).

(Manuscript received December 9, 1985; revision accepted for publication May 3, 1986.) 